\title{
Non-structural Enterotoxin (NSP4) Gene based Molecular Characterization of Caprine and Ovine Rotavirus A, India
}

\author{
Shubhankar Sircar ${ }^{1,2}$ (D) Prashant Kumar ${ }^{2}$, Mohd Ikram Ansari ${ }^{1}$, Sudipta Bhat ${ }^{1}$, \\ Jobin Jose Kattoor ${ }^{3,}$ O.R. Vinodhkumar ${ }^{4}$, Ranjit Sah ${ }^{5}$ (D), Kuldeep Dhama ${ }^{6 *}$ (D) \\ and Yashpal Singh Malik ${ }^{1,7 *}$ (D)
}

${ }^{1}$ Division of Biological Standardization, ICAR-Indian Veterinary Research Institute, Izatnagar, Bareilly - 243122, Uttar Pradesh, India.

${ }^{2}$ Amity Institute of Virology and Immunology, J-3 Block, Amity University, Sector - 125, Noida - 201313 ,

Uttar Pradesh, India.

${ }^{3}$ Animal Disease Diagnostic Laboratory, Purdue University, West Lafayette, Indiana, USA.

${ }^{4}$ Division of Epidemiology, ICAR-Indian Veterinary Research Institute, Izatnagar, Bareilly, Uttar Pradesh, India.

${ }^{5}$ Department of Microbiology, Tribhuvan University Teaching Hospital, Institute of Medicine, Kathmandu,

Nepal.

${ }^{6}$ Division of Pathology, ICAR-Indian Veterinary Research Institute, Izatnagar, Bareilly - 243 122, Uttar Pradesh, India.

${ }^{7}$ College of Animal Biotechnology, Guru Angad Dev Veterinary and Animal Sciences University, Ludhiana 141004, Punjab, India.

\begin{abstract}
Rotavirus A (RVA) causes viral gastroenteritis in humans and animals, including calves, piglets, and foals. The current study reports the genetic characterization of the full-length enterotoxin gene, NSP4, from caprine and ovine species. Upon characterizing eight full-length NSP4 genes by sequencing, it was found that the four caprine and three ovine RVAs NSP4 genes are of E2 genotype and the sole ovine RVA isolate was found to be of E1 genotype. In the sequence and phyloanalysis of the NSP4 gene the seven E2 genotypes clustered with bovine, human, and caprine isolates from India and Bangladesh, respectively. The E1 genotype of ovine RVA was closer to human RVA isolate from India. The nucleotide per cent identity analysis revealed that all E2 genotype strains of caprine and ovine species ranged from $\mathbf{8 8 . 4 \%}$ to $\mathbf{9 0 . 4 \%}$ and it was found common to both the reference human RVA isolates DS-1 and AU-1. Whereas, the E1 genotype ovine strain clustered with human RVA isolates with $93.1 \%$ nucleotide per cent identity. The RVA strains circulating in caprine and ovine populations may share a common origin which is usually found in artiodactyl species because humans share a common dwelling with animals. Future studies are needed to confirm these findings of their relationship with humans and large animals.

Keywords: Rotavirus, caprine, ovine, NSP4, enterotoxin, sequencing, phylogenetic analysis
\end{abstract}

*Correspondence: malikyps@gmail.com;

(Received: October 02, 2020; accepted: November 09, 2020)

kdhama@rediffmail.com

Citation: Sircar S, Kumar P, Ansari MI, et al. Non-structural Enterotoxin (NSP4) Gene based Molecular Characterization of Caprine and Ovine Rotavirus A, India. J Pure App/ Microbiol. 2020;14(4):2303-2311. doi: 10.22207/JPAM.14.4.09

(C) The Author(s) 2020. Open Access. This article is distributed under the terms of the Creative Commons Attribution 4.0 International License which permits unrestricted use, sharing, distribution, and reproduction in any medium, provided you give appropriate credit to the original author(s) and the source, provide a link to the Creative Commons license, and indicate if changes were made. 


\section{INTRODUCTION}

Rotavirus A (RVA) is among the leading causes of virus mediated gastroenteritis in humans and animals worldwide ${ }^{1}$. In livestock, RVA causes severe enteric infection in calves, piglets, and foals ${ }^{2}$. RVAs belong to the family Reoviridae which possesses 11 dsRNA segmented genome which encodes for six structural (VP1-4 and VP6-7) and six non-structural proteins (NSP1-6). On the basis of group-specific capsid protein VP6 gene, RVA is classified into nine species, namely A-I (RVA, RVB.... RVI). Of them, three species (RVA, RVB, \& RVC) have been reported in small ruminants ${ }^{3}$. RVAs have been studied extensively for domesticated species like bovine, porcine and humans, but caprine and ovine species have remained neglected ${ }^{4}$. Apart from RVs other enteric viruses are being discovered and studied which are also associated with diarrhoeal problems in small ruminants ${ }^{5-7}$.

Among the different proteins of rotaviruses, NSP4 plays the role of viral enterotoxin, which has been described to induce diarrhoea in suckling mice ${ }^{8}$. This discovery led to an increase in scientific interest to understand the role of the NSP4 enterotoxin gene in inducing diarrhoea in different animals and human neonates. NSP4, consisting of 175 amino acids, is an endoplasmic reticulum (ER) specific glycoprotein that has a role in viral pathogenesis and morphogenesis ${ }^{9}$. It has three hydrophobic domains, viz - $\mathrm{H} 1$ domain (7-21 aa), $\mathrm{H} 2$ domain (29-47 aa), and H3 domain (67-85 aa), and a coiled alpha helix domain stretches from 95-137 $\mathrm{aa}^{1}$. The amino-terminus region is located from 1-44 aa inside the lumen of ER, whereas 45175 aa stretch towards carboxyl-terminus contains the cytoplasmic tail (CT) known for key biological functions related to the protein, which includes a variation of $\mathrm{Ca}^{2+}$ homeostasis by discharging $\mathrm{Ca}^{2+}$ from the $\mathrm{ER}^{10-12}, \mathrm{Ca}^{2+}$ and VP4 binding ${ }^{1}$, permeabilization into the plasma membrane ${ }^{13}$, recruiting the double-layered particle to the lumen of ER to be matured into triple-layered particle ${ }^{14,15}$, and induction of diarrhoea in neonatal mice ${ }^{8,16,17}$.

So far, 27 E genotypes (E1-E27) have been identified in different animal and human species established on a $85 \%$ identity cut-off value for the NSP4 gene ${ }^{18,19}$. Genotypes E1, E2, and E3 have been reported more commonly ${ }^{18}$. Usually, all the NSP4 genotypes tend to segregate according to the RVA host species ${ }^{20}$ suggesting the dominance of specific genotypes for a particular species. To date, the RVA NSP4 and other genes of RVs have been analysed in more detail for human ${ }^{21-24}$, bovine ${ }^{25}$, porcine ${ }^{26}$, and avian species ${ }^{27}$. However, small ruminants remain the least studied species worldwide. RVA infection has been reported from all over the world, but reports from India are scanty, especially from caprine and ovine. In this report, we characterize caprine and ovine RVAs based on full-length enterotoxin gene NSP4 $(n=8)$ to identify their genotype difference and sequence variability.

\section{MATERIALS AND METHODS}

Sampling, processing, and viral RNA extraction

The collection of samples was done from goat kids and lambs that were below six months of age, irrespective of signs of diarrhoea. Specimens were processed by preparing a $10 \%$ suspension in $1 \mathrm{X}$ PBS and stored further at $-20^{\circ} \mathrm{C}$ for long time storage. The viral RNA was isolated using QIAzol Lysis Reagent (QIAGEN, USA) was suspended in 20 $\mu$ l of nuclease-free water (NFW) (QIAGEN, Hilden, Germany), and kept at $-20^{\circ} \mathrm{C}$ until further use.

\section{cDNA preparation by Reverse Transcription}

Initially, $15 \mu \mathrm{l}$ (100-200 ng) of viral RNA was mixed with $1.0 \mu \mathrm{l}(100 \mathrm{ng} / \mu \mathrm{l})$ of random hexamer (QIAGEN, Hilden Germany) and $1 \mu$ of DMSO (MB grade, Merck, Darmstadt, Germany) followed by incubation at $95^{\circ} \mathrm{C}$ for $5 \mathrm{~min}$ and 10 min snap chilling on ice. Simultaneously, $5 X$ RT buffer, $1 \mu$ l of $10 \mathrm{mM}$ dNTPs (QIAGEN, Hilden Germany), $1 \mu$ l of (40U) RNase Inhibitor Ribolock ${ }^{T M}$ (Fermentas, Vilnius, Lithuania), and $1 \mu \mathrm{l}$ of M-MLV RT enzyme (Promega, Madison, USA) were mixed accordingly and added to the snap chilled viral RNA mix making the final volume of the reaction to 25 $\mu l$ and kept at $37^{\circ} \mathrm{C}$ for $60 \mathrm{~min}$. The RT enzyme was inactivated by incubating the reaction at $80^{\circ} \mathrm{C}$ for 5 min. Thereafter, the cDNA prepared was employed in diagnosing RVA using custom-designed primers. Molecular detection of rotavirus and NSP4 amplification

The RVA presence in the fecal samples was detected employing a degenerate primer pair based on the VP6 gene by the RT-PCR, as described earlier ${ }^{28}$. Consecutively, the positive samples were subjected to PCR amplification 
for the full-length NSP4 enterotoxin gene. We used published primers to amplify the full-length gene (742 bp) as described earlier ${ }^{25}$. The primer name, sequence and the amplicon size of the VP6 and NSP4 gene used in the diagnosis and characterization of RVA isolates are given in Table 1. Following the amplification of desired products, the amplicons thus generated were cloned and sequenced in pDrive TA cloning vector according to a previous protocol ${ }^{29}$. The quality of each sequence thus generated was analyzed using the Finch TV (Geospiza, Inc. UK) software version 1.4, and the sequence identity was verified using the BLAST software in GenBank (http://blast.ncbi.nlm.nih. gov/Blast.cgi).

Eight isolates showing positive results in PCR were cloned and sequenced which was outsourced to M/s Eurofins Genomics, Bangalore. Out of the 08 isolates, four samples each from caprine and ovine origin were characterized. The sequence database generated on NSP4 genes was submitted to NCBI GenBank nucleotide repository under accession numbers MT998256 to MT998263. The strain name, place of collection, species, length, and accession numbers is given in (Table 2).

\section{Phylogenetic analysis}

Phylogenetic analysis was performed for RVA NSP4 gene with different isolates from India and worldwide. A total of 08 strains of the current study were subjected to phylogenetic analyses with 57 sequences from different species all over the world retrieved from the NCBI database (Fig. 1). The analysis was done using the MEGA 7.0 software ${ }^{30}$. In both cases, the evolutionary history was obtained using the Maximum Likelihood (ML) method based on the Tamura-3 parameter model for computing the distances with the support of 1000 bootstrap replicates. A separate gamma distribution was used to model evolutionary frequency differences between the sites.

Per cent identity calculation and comparison of Inter-Species Variable Domain (ISVD) region

For per cent identity calculation, we analyzed current study sequences in MegAlign software packaged in DNASTAR where sequences were aligned by ClustalW, and individual distances among them were calculated. Furthermore, the rotavirus genotyping web-based tool hosted by ViPRBRC for RVA classification (https://www. viprbrc.org) was used to infer the E genotypes of all NSP4 sequences. The ORFs of all individual genes

Table 1. Primers used for the diagnosis and characterization of small ruminant origin RVAs using RT-PCR assay

\begin{tabular}{lllll}
\hline Gene & Primer Name & Sequences 5'------ 3' & Amplicon Size & Ref. \\
\hline VP6 & RVA-D-F & TTTGATCACTAAYTATTCACC & 226 bp & 28 \\
VP6 & RVA-D-R & GGTCACATCCTCTCACTA & & \\
NSP4 & NSP4 (1-28) [+] & GGCTTTWAAAAGTTCTGTTCCGAGAGAG & 743 bp & 25 \\
NSP4 & NSP4 (722-743) [-] & TAAGACCRTTCCYTCCATTAAC & \\
\hline
\end{tabular}

Table 2. Randomly selected isolates from different states of Northern and Southern India were submitted in the NCBI GenBank database

\begin{tabular}{|c|c|c|c|c|c|}
\hline S.No. & Strain Name & Place of collection & Species & Length (bp) & Accession No. \\
\hline 1 & K-UP86 & Uttar Pradesh & Caprine & 724 & MT998256 \\
\hline 2 & K-UK95 & Uttarakhand & Caprine & 724 & MT998257 \\
\hline 3 & K-KAR110 & Karnataka & Caprine & 714 & MT998258 \\
\hline 4 & K-TN102 & Tamil Nadu & Caprine & 719 & MT998259 \\
\hline 5 & L-TN76 & Tamil Nadu & Ovine & 647 & MT998260 \\
\hline 6 & L-RAJ32 & Rajasthan & Ovine & 726 & MT998261 \\
\hline 7 & L-RAJ54 & Rajasthan & Ovine & 750 & MT998262 \\
\hline 8 & L-KAR65 & Karanataka & Ovine & 726 & МT998263 \\
\hline
\end{tabular}


were translated theoretically using the EditSeq tool of DNASTAR. A comparison of the pre-defined interspecies variable domain (ISVD) region was made with the assistance of the Protean tool the DNASTAR software package.

\section{RESULTS \\ Phylogenetic analysis}

The phylogenetic analysis of 8 NSP4 genes of the current study sequence revealed 7 ( 4 caprine and 3 ovines) of E2 genotype and 1 (ovine)
E1 genotype (Fig. 1). This observation was also confirmed by the web-based rotavirus genotyping tool of ViPRBC. As per the previous literature E1 genotype for ovine RVA strain has never been reported in India earlier. In phylogenetic analysis, all the E2 type strains of the current study clustered inside a major clade comprising different E2 genotype isolates from worldwide. Out of the four caprine strains of the current study, threebranched alongside bovine RVA isolates from India whereas one appeared alongside a Bangladeshi

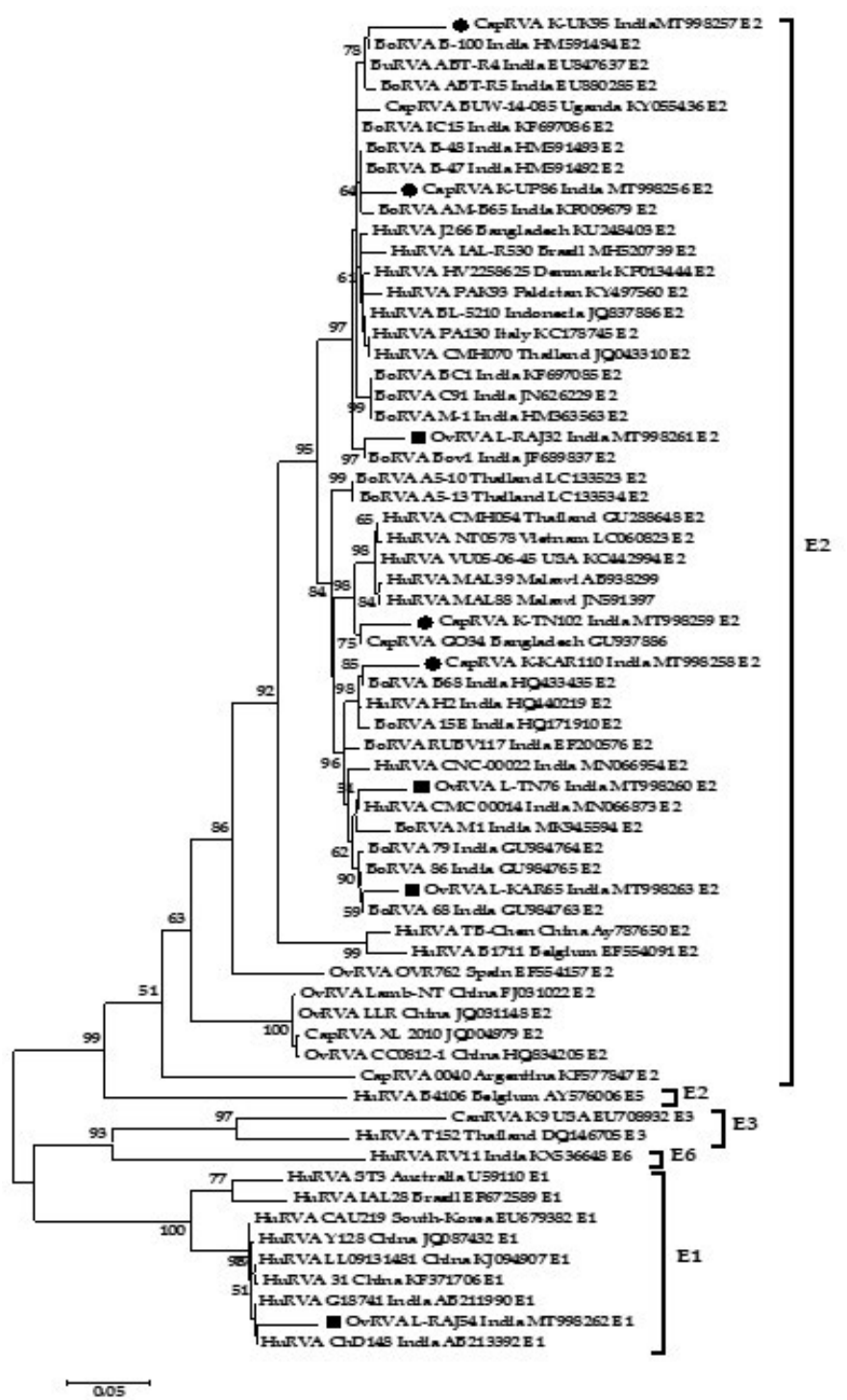

Fig. 1: Phylogenetic analysis of small ruminant RVA based on the full-length NSP4 gene. Caprine and ovine strains have been depicted with a black circle $(\bullet)$ and black square $(\boldsymbol{\square})$ respectively. The tree is divided into E2 major and an E1 minor clade which comprises current study strains. 


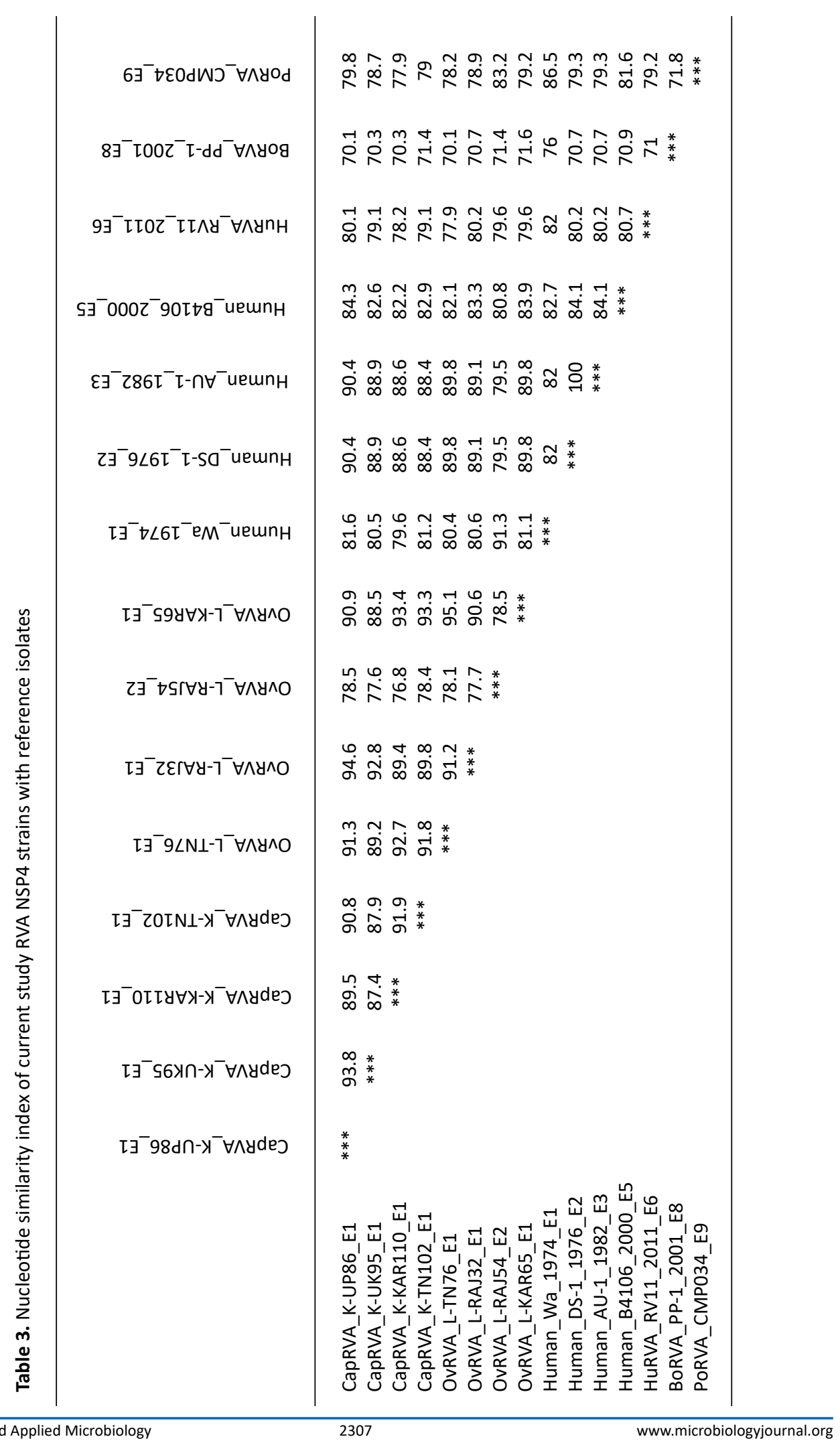


caprine RVA strain. Four ovine strains of the current study branched differently; two isolates from Rajasthan branched with bovine RVA isolates from India. At the same time, one each from Tamil Nadu and Rajasthan were closely related to human RVA isolates from India. The ovine RVA strain L-RAJ54 clustered inside the minor clade comprising human RVA of the E1 genotype.

\section{Per cent identity analysis}

The per cent identity analysis was done with the selected reference NSP4 genotypes which have been reported in humans and domesticated artiodactyl type species like bovine and porcine. The nucleotide per cent identity analysis revealed that all the E2 genotype strains of caprine and ovine species of the current study showed the highest (88.4\% to $90.4 \%$ ) and equal per cent identity with two reference human RVA isolates DS-1 (AF174305) and AU-1 (D89873) (Table 3). Ovine strain L-RAJ54 showed the highest nucleotide similarity percentage (91.3\%) with reference human RVA E1 genotype isolate Wa (K02032). The current study caprine and ovine strains shared 87.4 to $93.8 \%$ and 77.7 to $95.1 \%$ of nucleotide similarity among themselves, respectively. This showed that ovine samples were more divergent among them with respect to caprine samples.

Amino acid sequence comparison of RVA NSP4 ISVD

The NSP4 strains were translated theoretically and aligned using the MegAlign software to observe any crucial changes in the ISVD region of NSP4 C-terminal (Fig. 2). The observations revealed that E2 genotype strains of current study strains contain more variation in comparison to $\mathrm{E} 1$ type when aligned along with reference isolates. E2 type strains showed some number of varied amino acid residues in the ISVD region (131-141 aa) whereas the single E1 type ovine strain L-RAJ54 showed variance at residue position 131, 134, 137, and 141 only.

\section{A}

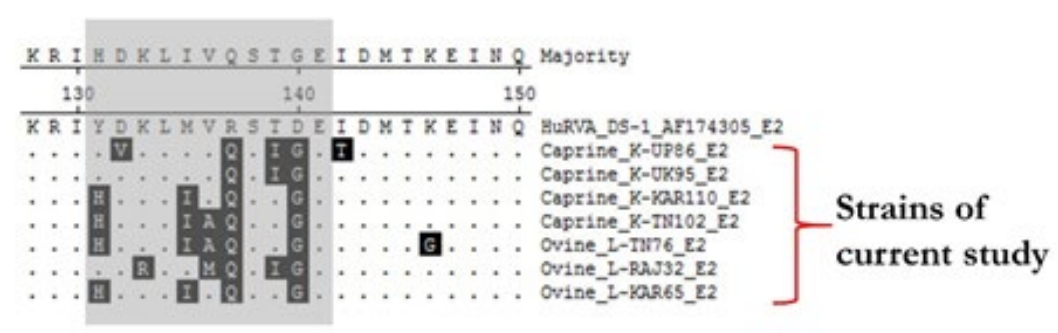

B

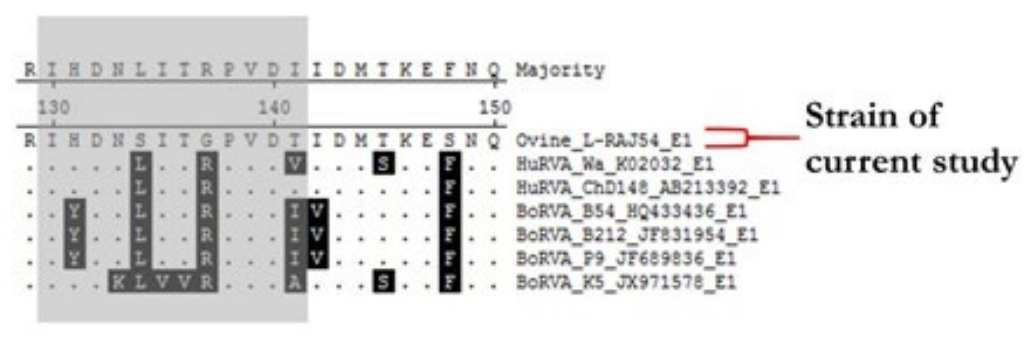

Fig. 2. Alignment of an interspecies variable domain (ISVD) of NSP4 from the current study and reference isolates. (A) Alignment depicts the amino acid sequence variation in E2 type strains (B) Alignment depicts the amino acid sequence variation in E1 type strains. Variable residues have been highlighted in black colour showing variance in sequences. 


\section{DISCUSSION}

RVAs are known to cause diarrhoea in human neonates ${ }^{31}$, calves, and piglets ${ }^{32}$, but their aetiology has not been studied well in small ruminants. The current study reports the presence of RVAs in the caprine and ovine population of India along with the characterization of its major enterotoxin gene for the first time in India. However, few reports of prevalence emerged from India in the past for small ruminants ${ }^{33-37}$ but these reports failed to provide data on sequencebased characterization of RVA in small ruminants. Therefore, this study was designed to decipher the circulating potential of RVA in the small ruminant population of India as well as to characterize them based on sequence and phylogeny.

The phylogenetic analysis revealed a diverse population of ovine and caprine RVA based on the full-length NSP4 gene where in seven E2 type strains of the present study branched into different sub-clusters within the major E2 clade. One ovine RVA sample showed E1 genotype specificity which was found closer to a human RVA strain ChD148 (GenBank record only) of India. These observations point towards the diverse origin of RVAs in the Indian small ruminant population. Closeness to human and bovine type RVA isolates also suggest the ongoing interspecies transmission occurring between these ungulates and other mammals including humans. We aligned and observed the NSP4 amino acid sequences of the present study and found that strains possess a significant number of amino acid residue changes in the interspecies variable domain of the NSP4 C-terminus. This observation also supports the regarding the sequence and phylogenetic variation among small ruminant RVAs. Nevertheless, it will be interesting to observe whether these amino acid changes will lead to any alteration in the infectivity of these viral strains.

Overall the data presented in the study hypothesize that RVA strains circulating in these small ruminant populations may share a common origin which is usually found in artiodactyl species, but future studies are needed to confirm these findings. This hypothesis is reasonable because humans, large and small ruminants share a common dwelling place. The data from the prevalence also warrants strict surveillance measures to be taken in the future to know about the circulating genotypes of small ruminant RVAs.

\section{ACKNOWLEDGMENTS}

Authors acknowledge and express thanks to their respective Institutes and Universities. Help of Shanmuganathan in sampling is acknowledged. YSM acknowledges the Education Division, ICAR, Govt. of India for National Fellowship.

\section{CONFLICT OF INTEREST}

The authors declare that there is no conflict of interest.

\section{FUNDING}

None.

\section{AUTHORS' CONTRIBUTION}

All the authors substantially contributed to the conception, compilation, checking, and approving the final version of the manuscript, and agree to be accountable for its contents.

\section{DATA AVAILABILITY}

All datasets generated or analyzed during this study are included in the manuscript and/or the Supplementary Files.

\section{ETHICS STATEMENT}

Not applicable.

\section{REFERENCES}

1. Desselberger U. Rotaviruses. Virus Res. 2014;190:7596. doi: 10.1016/j.virusres.2014.06.016

2. Dhama K, Chauhan R, Mahendran M, Malik S. Rotavirus diarrhea in bovines and other domestic animals. Vet Res Commun. 2009;33(1):1-23. doi: 10.1007/s11259008-9070-x

3. Martella V, Decaro N, Buonavoglia C. Enteric viral infections in lambs or kids. Vet Microbiol. 2015;181(12):154-160. doi: 10.1016/j.vetmic.2015.08.006

4. Papp H, Malik YS, Farkas SL, Jakab F, Martella V, Banyai K. Rotavirus strains in neglected animal species including lambs, goats and camelids. Virus Disease. 2014;25(2):215-222. doi: 10.1007/s13337-014-0203-2

5. Malik YS, Sircar S, Dhama K, et al. Molecular epidemiology and characterization of picobirnaviruses in small ruminant populations in India. Infect Genet Evol. 2018;63:39-42. doi: 10.1016/j.meegid.2018.05.011

6. Bachofen $\mathrm{C}$, Vogt $\mathrm{H}-\mathrm{R}$, Stalder $\mathrm{H}$, et al. Persistent infections after natural transmission of bovine viral diarrhoea virus from cattle to goats and among goats. Vet Res. 2013;44(1):32. doi: 10.1186/1297-9716-44-32

7. Amer HM. Bovine-like coronaviruses in domestic and 
wild ruminants. Anim Health Res Rev. 2018;19(2):113124. doi: $10.1017 / \mathrm{S} 1466252318000117$

8. Ball JM, Tian P, Zeng CQ-Y, Morris AP, Estes MK. Agedependent diarrhea induced by a rotaviral nonstructural glycoprotein. Science. 1996;272(5258):101-104. doi: 10.1126/science.272.5258.101

9. Zhang M, Zeng CQ-Y, Morris AP, Estes MK. A functional NSP4 enterotoxin peptide secreted from rotavirusinfected cells. J Virol. 2000;74(24):11663-11670. doi: 10.1128/JVI.74.24.11663-11670.2000

10. Dong $Y$, Zeng CQ-Y, Ball JM, Estes MK, Morris AP. The rotavirus enterotoxin NSP4 mobilizes intracellular calcium in human intestinal cells by stimulating phospholipase C-mediated inositol 1 , 4, 5-trisphosphate production. Proceedings of the National Academy of Sciences. 1997;94(8):3960-3965. doi: 10.1073/pnas.94.8.3960

11. Hyser JM, Collinson-Pautz MR, Utama B, Estes MK. Rotavirus disrupts calcium homeostasis by NSP4 viroporin activity. MBio. 2010;1(5). doi: 10.1128/ mBio.00265-10

12. Tian P, Estes MK, Hu Y, Ball JM, Zeng C, Schilling WP. The rotavirus nonstructural glycoprotein NSP4 mobilizes $\mathrm{Ca} 2+$ from the endoplasmic reticulum. J Virol. 1995;69(9):5763-5772. doi: 10.1128/JVI.69.9.57635772.1995

13. Newton K, Meyer JC, Bellamy AR, Taylor JA. Rotavirus nonstructural glycoprotein NSP4 alters plasma membrane permeability in mammalian cells. J Virol. 1997;71(12):9458-9465. doi: 10.1128/JVI.71.12.94589465.1997

14. Au K-S, Mattion NM, Estes MK. A subviral particle binding domain on the rotavirus nonstructural glycoprotein NS28. Virology. 1993;194(2):665-673. doi: 10.1006/viro.1993.1306

15. O'brien JA, Taylor JA, Bellamy A. Probing the structure of rotavirus NSP4: a short sequence at the extreme $C$ terminus mediates binding to the inner capsid particle. J Virol. 2000;74(11):5388-5394. doi: 10.1128/ JVI.74.11.5388-5394.2000

16. Horie $Y$, Nakagomi $O$, Koshimura $Y$, et al. Diarrhea induction by rotavirus NSP4 in the homologous mouse model system. Virology. 1999;262(2):398-407. doi: 10.1006/viro.1999.9912

17. Jagannath $\mathrm{M}$, Kesavulu $\mathrm{M}$, Deepa $\mathrm{R}$, et al. $\mathrm{N}$-and $C$-terminal cooperation in rotavirus enterotoxin: novel mechanism of modulation of the properties of a multifunctional protein by a structurally and functionally overlapping conformational domain. J Virol. 2006;80(1):412-425. doi: 10.1128/JVI.80.1.412425.2006

18. Matthijnssens J, Ciarlet M, McDonald SM, et al. Uniformity of rotavirus strain nomenclature proposed by the Rotavirus Classification Working Group (RCWG). Arch Virol. 2011;156(8):1397-1413. doi: 10.1007/ s00705-011-1006-z

19. RCWG. Rotavirus Classification Working Group: Newly assigned genotypes. https://rega.kuleuven.be/cev/ viralmetagenomics/virus-classification/rcwg

20. Ciarlet M, Liprandi F, Conner M, Estes M. Species specificity and interspecies relatedness of NSP4 genetic groups by comparative NSP4 sequence analyses of animal rotaviruses. Arch Virol. 2000;145(2):371-383. doi: $10.1007 / \mathrm{s} 007050050029$

21. Araujo IT, Heinemann MB, Mascarenhas JDAP, Assis RMS, Fialho AM, Leite JPG. Molecular analysis of the NSP4 and VP6 genes of rotavirus strains recovered from hospitalized children in Rio de Janeiro, Brazil. J Med Microbiol. 2007;56(6):854-859. doi: 10.1099/ jmm.0.46787-0

22. Fredj $\mathrm{MBH}$, Zeller $\mathrm{M}$, Fodha I, et al. Molecular characterization of the NSP4 gene of human group A rotavirus strains circulating in Tunisia from 2006 to 2008. Infect Genet Evol. 2012;12(5):997-1004. doi: 10.1016/j.meegid.2012.02.011

23. Gonzalez-Ochoa G, Menchaca GE, Hernandez CE, Rodriguez C, Tamez RS, Contreras JF. Mutation distribution in the NSP4 protein in rotaviruses isolated from Mexican children with moderate to severe gastroenteritis. Viruses. 2013;5(3):792-805. doi: 10.3390/v5030792

24. Tavares TdM, Brito WMEDd, Fiaccadori FS, et al. Molecular characterization of the NSP4 gene of human group A rotavirus samples from the West Central region of Brazil. Mem Inst Oswaldo Cruz. 2008;103(3):288294. doi: $10.1590 /$ S0074-02762008000300011

25. Malik YS, Kumar N, Sharma K, et al. Molecular analysis of non structural rotavirus group A enterotoxin gene of bovine origin from India. Infect Genet Evol. 2014;25:2027. doi: 10.1016/j.meegid.2014.04.004

26. Saurabh S, Sircar S, Kattoor JJ, et al. Analysis of structure-function relationship in porcine rotavirus A enterotoxin gene. J Vet Sci. 2018;19(1):35-43. doi: 10.4142/jvs.2018.19.1.35

27. Mori $Y$, Borgan MA, Ito N, Sugiyama M, Minamoto $N$. Sequential analysis of nonstructural protein NSP4s derived from group A avian rotaviruses. Virus Res. 2002;89(1):145-151. doi: 10.1016/S01681702(02)00112-0

28. Mondal A, Sharma K, Malik YS, Joardar SN. Detection of group a rotavirus in faeces of diarrhoeic bovine porcine and human population from eastern India by reverse transcriptase-polymerase chain reaction. $A d v$ Anim Vet Sci. 2013;1(1S):18-19.

29. Kattoor JJ, Saurabh S, Malik YS, et al. Unexpected detection of porcine rotavirus $C$ strains carrying human origin VP6 gene. Vet Q. 2017;37(1):252-261. doi: 10.1080/01652176.2017.1346849

30. Kumar S, Stecher G, Tamura K. MEGA7: molecular evolutionary genetics analysis version 7.0 for bigger datasets. Mol Biol Evol. 2016;33(7):1870-1874. doi: 10.1093/molbev/msw054

31. Estes MK. Rotaviruses. Fields Virology. 2007:19171974.

32. Papp H, Laszlo B, Jakab F, et al. Review of group A rotavirus strains reported in swine and cattle. Vet Microbiol. 2013;165(3-4):190-199. doi: 10.1016/j. vetmic.2013.03.020

33. Singh U, Singh R, Singh AP, Yadav SK, Sircar S, Malik YS. Detection and characterization of caprine and ovine rotaviruses, India. Indian J Anim Sci. 2017;87(11):13581361.

34. Reddy G, Kumari A, Mishra A, et al. Prevalence of groupa rotavirus in diarrhoeic goat kids from organized 
goat farms. Indian I Comp Immunol Microbiol Infect Dis. 2014;35(1):9-12.

35. Wani S, Bhat M, Nawchoo R, Munshi Z, Bach A. Evidence of rotavirus associated with neonatal lamb diarrhoea in India. Trop Anim Health Prod. 2004;36(1):27-32. doi: 10.1023/B:TROP.0000009523.32254.45

36. Gazal S, Taku A, Kumar B. Predominance of rotavirus genotype G6P [11] in diarrhoeic lambs. Vet J. 2012;193(1):299-300. doi: 10.1016/j.tvjl.2011.11.018

37. Gupta V, Pandey M, Nayak A, Rajoriya S, Bordoloi S. Polyacrylamide gel electrophoresis and silver staining for detection of rotavirus in goat fecal samples. Journal of Pharmacognosy and Phytochemistry. 2019;8(3):472475. 